\title{
Association of Single Nucleotide Polymorphism rs11172113 of LRP1 Gene with Migraine in South Indian Population - A Study \\ ${ }^{* 1}$ Gouri Srinivasan, ${ }^{2}$ Uddanapalli Sreeramulu Shoba, ${ }^{3}$ Jyothsna Gundlapally, ${ }^{4}$ Kumaresan Kuppamuthu \\ ${ }^{1,4}$ Department of Biotechnology, Kumaraguru College of Technology, Coimbatore, Tamil Nadu, India \\ ${ }^{2}$ Department of Chemistry, Kumaraguru College of Technology, Coimbatore, Tamil Nadu, India \\ ${ }^{3}$ BioAxis DNA Research Centre Private Limited, Hyderabad, Telangana, India. \\ Email: gourisrini92@gmail.com; ussche@gmail.com,jyothsna@dnares.in,kumaresan.k.bt@kct.ac.in
}

Received: 01st April 2020, Accepted: 05th May 2020, Published: 30th June 2020

\begin{abstract}
Migraine is a weakening neurological disorder with a polygenic inheritance caused by multiple factors - both environmental and genetic. The variegated ethnicity of India makes it a fertile field for research into genetic of migraine. Approaches to migraine therapy based on its mechanism of action has led scholars to associate Single nucleotide polymorphisms (SNPs) of various genes with migraine to improve the understanding of genetics of classical and common migraine. One such SNP is rs11172113 of the LRP1 gene which is localized for common migraine. The association of this SNP in South Indian origin is considered in this study. The results of this study indicated that migraine is more prevalent among female population and female migraineurs exhibited $\mathrm{C} \rightarrow \mathrm{T}$ polymorphism to greater extent. This association could be attributed to the involvement of LRP1 locus and the NMDA glutamate receptor co-localization. A mutation in this locus might lead to increased glutamate levels which cause excititoxicity, thereby leading to neurodegeneration and neuronal damage and this might be the cause of headache in migraine.
\end{abstract}

Keywords

Migraine, LRP1 gene, SNP rs11172113, Common Migraine, Glutamate, Excitotoxicity

\section{Introduction}

Advances in genetics and neuroscience has paved way for the researchers to study a DNA sequence to find the cause for a disease or disorder. One such disorder, mysterious though common, is migraine. Migraine has till date no known cause or cure. It is a debilitating familial condition, characterised by recurrent unilateral headaches, mostly occurring in children, adolescents or in early adulthood. The recurrence frequency diminishes as the patient ages [1].

There are two kinds of migraine as classified by IHS - the classical migraine or migraine with aura and the common migraine or migraine without aura [2]. Even though migraine is recently found to be hereditary, the genetics underlying these two kinds are different. Developments in neurogenetics and its technology provide the researchers with a deeper understanding regarding the mechanisms involved in polygenic inheritance of migraine and the subsequent onset of the headache. By this, the SNPs are being associated to migraine. rs11172113 of the LRP1 gene is one such SNP which is associated with the common migraine [3]. The increasing prevalence of migraine in India, especially in females and its disability and burden is nearly the same as other diseases. Since there is no single cause for the disease, the research to find a cure is seriously hampered. Due to the heredity nature of the migraine, studying its genetics and genomics could result in localisation and association of a particular SNP to migraine, which could thereby lead to a clearer understanding of the disease.

\section{Materials and Methods}

A 28-member volunteer group profile is presented in Table - 1. From this it could be stated that with 8 males and 20 females between the age 15 and 50 years having a South Indian origin were interviewed and selected for the study. 8 members without migraine were the healthy control group. Among the remaining 20, 4 members had classical migraine and 16 had common migraine.

Volunteers were asked to provide a written informed consent. $5 \mathrm{ml}$ blood samples were collected in sterile vials containing EDTA. Until further analysis, these samples were stored at $-20^{\circ} \mathrm{C}$. Rapid non-enzymatic method (Bunce method - standard protocol of BioAxis DNA Research Centre, Hyderabad), was used to extract the genomic DNA from the blood samples. Agarose gel electrophoresis was performed for the confirmation of the presence of DNA [4]. Literature search of the previous studies led to the identification of LRP1 gene, whose FASTA sequence was obtained from the NCBI database and the SNP rs11172113, present in the gene [5]. About $200 \mathrm{bp}$ of the gene sequence containing the SNP was selected for amplification. The software, Primer3, was used to design the primer for the SNP. PCR amplification of the DNA samples were performed using the forward primer 5'ACTCAGAATGGAAGCGGAGA3' and the reverse primer 5'TTCAGATTCCTGCAGGCTCT3' and an annealing temperature of $58^{\circ} \mathrm{C}$. The amplicons obtained were outsourced to Bioserve India, Hyderabad, for 
sequencing using the ABI sequencer. The sequences were then aligned using CLUSTAL W and were compared to find the selected SNP [4].

Table 1: The Profile of the Volunteers in this Study

\begin{tabular}{|c|c|c|c|}
\hline \multirow[t]{3}{*}{ Sample/ Control } & \multirow[t]{3}{*}{ Gender } & \multirow{3}{*}{$\begin{array}{l}\text { Classical or } \\
\text { Common Migraine }\end{array}$} & \multirow{2}{*}{$\begin{array}{l}L R P 1 \\
\text { rs11172113 }\end{array}$} \\
\hline & & & \\
\hline & & & C to $\mathbf{T}$ \\
\hline S1 & $\mathrm{F}$ & Common & YES \\
\hline $\mathrm{S} 2$ & $\mathrm{~F}$ & Common & $\mathrm{NO}$ \\
\hline S3 & $\mathrm{F}$ & Common & YES \\
\hline S4 & $\mathrm{F}$ & Common & YES \\
\hline S5 & $\mathrm{F}$ & Classical & YES \\
\hline S6 & $\mathrm{F}$ & Common & YES \\
\hline S7 & $\mathrm{M}$ & Common & $\mathrm{NO}$ \\
\hline S8 & M & Classical & YES \\
\hline S9 & $\mathrm{F}$ & Common & $\mathrm{NO}$ \\
\hline $\mathrm{S} 10$ & $\mathrm{~F}$ & Classical & $\mathrm{NO}$ \\
\hline $\mathrm{S} 11$ & $\mathrm{~F}$ & Common & $\mathrm{NO}$ \\
\hline S12 & $\mathrm{F}$ & Common & YES \\
\hline S13 & $\mathrm{F}$ & Common & $\mathrm{NO}$ \\
\hline S14 & $\mathrm{F}$ & Classical & $\mathrm{NO}$ \\
\hline $\mathrm{S} 15$ & $\mathrm{M}$ & Common & $\mathrm{NO}$ \\
\hline S16 & $\mathrm{F}$ & Common & $\mathrm{NO}$ \\
\hline $\mathrm{S} 17$ & F & Common & $\mathrm{NO}$ \\
\hline S18 & $\mathrm{M}$ & Common & $\mathrm{NO}$ \\
\hline S19 & $\mathrm{F}$ & Common & $\mathrm{NO}$ \\
\hline S20 & $\mathrm{M}$ & Common & $\mathrm{NO}$ \\
\hline $\mathrm{C} 1$ & $\mathrm{M}$ & - & YES \\
\hline $\mathrm{C} 2$ & $\mathrm{~F}$ & - & YES \\
\hline $\mathrm{C} 3$ & $\mathrm{M}$ & - & $\mathrm{NO}$ \\
\hline $\mathrm{C} 4$ & $\mathrm{M}$ & - & YES \\
\hline $\mathrm{C} 5$ & $\mathrm{~F}$ & - & $\mathrm{NO}$ \\
\hline C6 & $\mathrm{F}$ & - & $\mathrm{NO}$ \\
\hline $\mathrm{C} 7$ & $\mathrm{~F}$ & - & $\mathrm{NO}$ \\
\hline $\mathrm{C} 8$ & $\mathrm{~F}$ & - & $\mathrm{NO}$ \\
\hline $\mathrm{F}-$ Female, $\mathrm{M}-\mathrm{N}$ & , C-Cor & ample & \\
\hline
\end{tabular}

\section{Results and Discussion}

The volunteer cohort includes 20 subjects with 5 male and 15 female migraineurs and 8 controls with 3 healthy males and 5 healthy females. From their profile, it is found that the occurrence of migraine in females is thrice that of males indicating that the female population is more likely to suffer from migraine than the males. Out of the 20, 16 were migraineurs without aura, but having sleepless nights, skipping meals, sensitivity to bright light as the triggers of the headache. This indicates that common migraine prevalence is more than classical migraine. The collected blood samples were subjected to DNA extraction. The presence of DNA was confirmed by agarose gel electrophoresis. The results involving rs11172113 of LRP1 gene indicates that 6 out of 16 common migraineurs and 3 out of 8 controls showed $\mathrm{C}$ to $\mathrm{T}$ polymorphism. Out of 3 male controls chosen 2 male controls showed polymorphism whose parents also did not report of migraine but among 5 female controls only one female control showed polymorphism.

The child of the female control was one of the individuals who had volunteered as a migraineur. This suggests that this case might be hereditary, but the mutation might have been dormant or had not been triggered in the parent. Also, it was noted that the female control's mother had a history of severe one-sided headaches though it was not diagnosed as migraine during that period. 


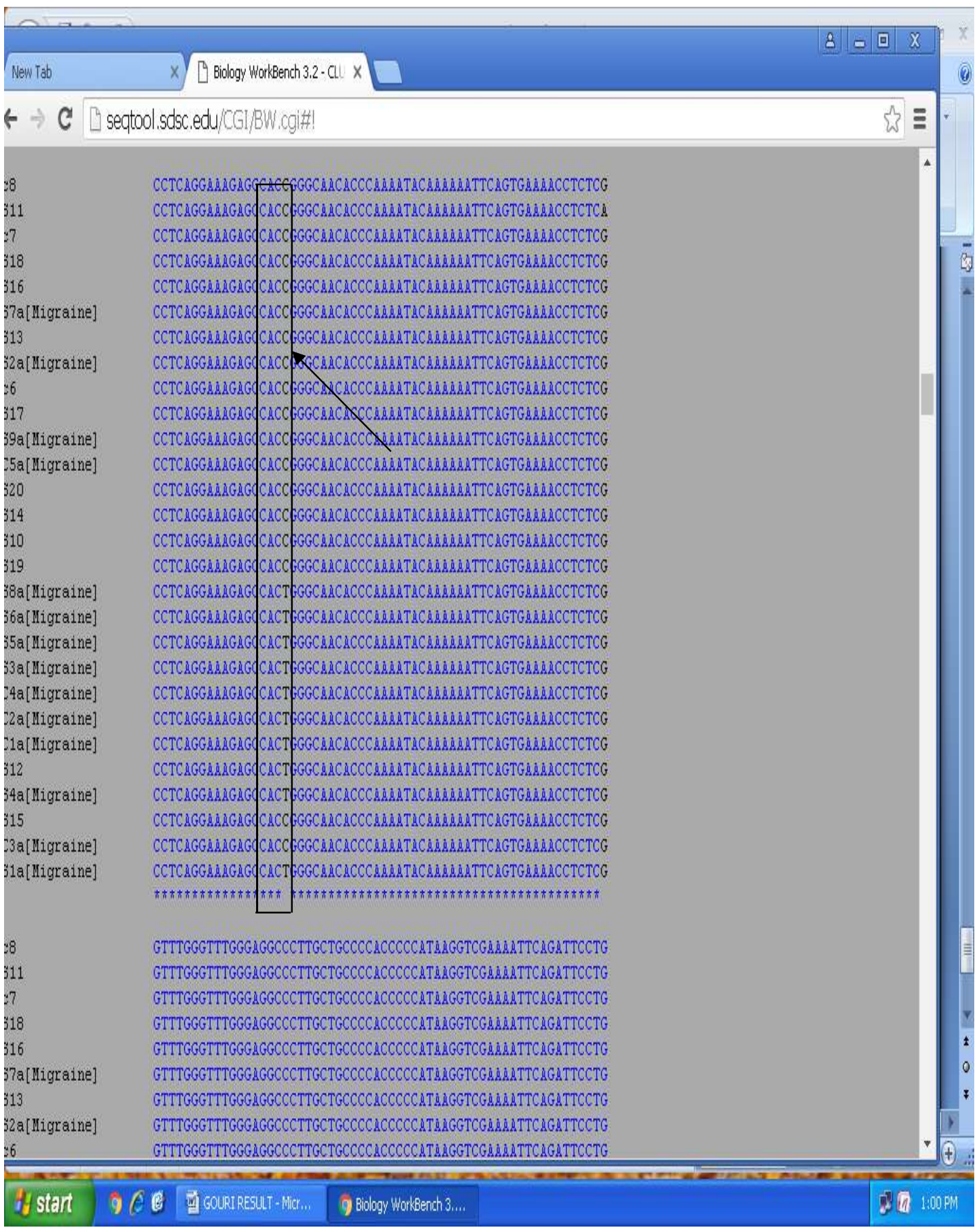

\section{Fig 1: Clustalw Result for LRP1 Gene - C to T Mutation}

The analysis for statistical significance was also carried out. 4 samples out of 20 migraineurs were classified as migraine patients with aura from their answers for the questionnaire. This implies that there are 16 common migraine individuals. 6 out of 16 samples showed polymorphism for $L R P 1$ gene. The chi square statistic is 0.0857 . The $\mathrm{p}$ value is 0.769 . This indicates that rs11172113 of LRPl gene does not statistically have significant association with migraine. The research with North Indian population has shown significant association of $L R P 1$ gene and SNP rs11172113 to common migraine [6]. Genome-wide association studies (GWAS) performed by Chasman et al., (2011), Schürks, (2012), Freilinger et al., (2012), showed that rs11172113 of LRP1 gene was found to have significant association with common migraine $[3,7,8]$. 
This could suggest that, probably for South Indian population, there could be other SNPs responsible or factors which would associate to migraine as in the case of Ran et al., (2014). Also, due to small sample size the results could have extreme variation [9].

Dwelling deeper to understand the clinical significance, it was found that all the four male common migraineurs did not show any association with the $L R P l$ gene but the male with classical migraine showed this $\mathrm{C} \rightarrow \mathrm{T}$ polymorphism of the LRP1 gene but not the $\mathrm{A} \rightarrow \mathrm{T}$ polymorphism of CACNA1A gene as it was expected (4). This suggests that probably for male migraineurs, a different SNP in a different gene could be the cause of migraine onset.

On analysing the 15 female migraineurs cohort, 3 were as classical migraineurs who showed $\mathrm{A} \rightarrow \mathrm{T}$ polymorphism for $C A C N A 1 A$ gene [4]. Among the three, only one showed both $\mathrm{A} \rightarrow \mathrm{T}$ polymorphism for $C A C N A 1 A$ gene and $\mathrm{C} \rightarrow \mathrm{T}$ polymorphism for $L R P 1$ gene. 5 showed association with and SNP rs11172113 of the LRPI gene in the remaining 12 female migraineurs. This though looks non - significant, considerable increase in association is noticed when it comes to female migraineurs, from a statistical point of view. It could as well have a greater significance on the clinical front.

The severe headache during migraine in people showing rs11172113 polymorphism in LRPl gene could be attributed to the following mechanism. LRPI locus is involved in vascular smooth muscle cell proliferation and modulation of the synaptic transition. The gene and NMDA glutamate receptor co-localize on neuronal cells to interact. Mutations in this gene could alter the interaction between LRPI and glutamate receptor. This points towards the participation of glutamate pathway in which glutamate, an excitatory neurotransmitter, interacts with the NMDA receptor for signal transduction. Excess glutamate is then cleared from synapse and finally glutamate is converted to glutamine. It is reported that glutamate levels increase during migraine attack. Increased glutamate leads to a mechanism called excitotoxicity where there is overstimulation of glutamate receptors which leads to excess influx of calcium ions in the postsynaptic cell, thereby causing neurodegeneration and neuronal damage. This might lead to headache during migraine [7,10,11].

\section{Conclusion}

In this study, the rs 11172113 polymorphism of $L R P 1$ gene was exhibited mainly by the female populations among the 7 common migraineurs out of 16 . The study gives more support to the concept that females are more likely to suffer from migraine than males. Though not significant, this could be attributed due to the multifactorial nature of migraine or probably the small sample size of the study. Also, parent-child combinations identified in this study which exhibited the polymorphism for rs11172113 might support the fact that migraine might be hereditary. Further, the study of parent-child relationship though few in numbers indicate that migraine may not be expressed in the next or even in second generation but can still be in the genetic make-up awaiting expression. The study confirms that a single gene or SNP cannot be associated for common migraine because the South Indian population has diversified lineages and ethnicity. It would also be safe to say that the environmental factors might not only be the cause but also maybe the trigger for some genetic mutations thus causing the onset of common migraine. A deeper knowledge of ethnicity and gender influence on the genes and an extensive research on the association of various SNPs to migraine could help in understanding of the migraine headache phase and probably lead to the discovery of a prevention or cure for the disorder.

\section{References}

[1] Victor M, Ropper AH. Adams and Victor's Principles of neurology, $7^{\text {th }}$ edition, 2001, Chapter 10.

[2] Headache Classification Committee of the International Headache Society (IHS), The international classification of headache disorders, (beta version), Cephalalgia, Vol:33-9, 2013, p. 629-808.

[3] Chasman, D. I., Schürks, M., Anttila, V., de Vries, B., Schminke, U., Launer, L. J., Terwindt, G.M., van den Maagdenberg, A.M., Fendrich, K., Völzke, H. \& Ernst, F., Genome-wide association study reveals three susceptibility loci for common migraine in the general population, Nature genetics, Vol:43-7, 2011, p.695698.

[4] Srinivasan, G., Gundlapally, J., \& Kuppamuthu, K., A Study on Association of Single Nucleotide Polymorphisms on CACNA1A Gene with Migraine in South Indian Population, HELIX, Vol:2, 2016, p.770772.

[5] http://www.ncbi.nlm.nih.gov/snp/?term=RS11172113.

[6] Ghosh, J., Pradhan, S., \& Mittal, B., Genome-Wide-Associated Variants in Migraine Susceptibility: A Replication Study From North India, Headache: The journal of head and face pain, Vol:53-10, 2013, p.15831594.

[7] Schürks, M, Genetics of migraine in the age of genome-wide association studies, The journal of headache and pain, Vol:13-1, 2012, p.1-9.

[8] Freilinger, T., Anttila, V., de Vries, B., Malik, R., Kallela, M., Terwindt, G. M., Pozo-Rosich, P., Winsvold, B., Nyholt, D.R., van Oosterhout, W.P. \& Artto, V., Genome-wide association analysis identifies susceptibility loci for migraine without aura, Nature genetics, Vol:44-7, 2012, p.777-782. 
[9] Ran, C., Graae, L., Magnusson, P. K., Pedersen, N. L., Olson, L., \& Belin, A. C., A replication study of GWAS findings in migraine identifies association in a Swedish case-control sample, BMC medical genetics, Vol:15-1, 2014, p.1

[10] International Headache Genetics Consortium, Genome-wide association study of migraine implicates a common susceptibility variant on 8q22. 1, Nature genetics, Vol:42-10, 2010, p.869-873.

[11] Silberstein, S. D., \& Dodick, D. W., Migraine genetics: part II, Headache: The journal of head and face pain, Vol:53-8, 2013, p.1218-1229. 